\title{
Loading on a rigid target from close proximity underwater explosions
}

\author{
Mark Riley ${ }^{\mathrm{a}, *}$, Malcolm Smith ${ }^{\mathrm{a}}$, J.E. van Aanhold ${ }^{\mathrm{b}}$ and Niklas Alin ${ }^{\mathrm{c}}$ \\ ${ }^{a}$ Defence Research and Development Canada-Atlantic, Dartmouth, NS, Canada \\ ${ }^{\mathrm{b}}$ TNO Delft, Delft, The Netherlands \\ ${ }^{\mathrm{c}}$ FOI Defence and Security Systems and Technology - Grindsjön, Grindsjön, Sweden
}

Received 26 April 2011

Revised 31 August 2011

\begin{abstract}
The study describes recent simulation results for underwater explosions in close-proximity to rigid targets. Simulations are performed using Chinook, an Eulerian computational fluid dynamics (CFD) code. Predicted target loadings are compared with measurements taken from a series of experiments conducted under an international collaboration between Canada, The Netherlands, and Sweden. The simulations of the rigid target tests focused on the modelling of gas bubble collapse and water jetting behaviour. Both two-dimensional and three-dimensional simulations were performed. It was found that the two-dimensional analyses produced good bubble periods and reasonable impulse loading compared to experimental data. The time of arrival of the bubble collapse and water jetting were found to be very mesh dependent and refining the mesh did not always produce better results. The two-dimensional approach provides a good initial understanding of the problem for a reasonable computational effort. The three-dimensional simulations were found to produce improved impulse predictions. The numerical gas bubble radii time histories are also compared to empirical time histories.
\end{abstract}

Keywords: Underwater explosion, shock, gas bubble dynamics, water jetting, computational fluid dynamics, marine structures

\section{Introduction}

Underwater explosions (UNDEX) that are within twice the radius of the explosion gas bubble of a target are referred to as close-proximity explosions. At these ranges, the dynamics of the gas bubble are influenced by the geometry of the target (in the case of a rigid target), and possibly also by the deformation of the target (in the case of a responding target). Many studies of close proximity UNDEX have been primarily concerned with shock wave interactions with a target and damage (e.g. [12,20,25,28-31,34]). Other studies have examined the effect of the target on the dynamics of the gas bubble (e.g. [8,13]), while still others have examined the fully-coupled interaction between the gas-bubble dynamics and the target response (e.g. [1-5,9,13,14,23,35-37,39,40]). The present study is primarily concerned with the bubble behaviour in close-proximity to a rigid target, and the loading experienced by the target from the collapsing gas bubble and water jetting.

Experimental studies of close-proximity gas bubble interaction with a target include a series of studies conducted at DRDC Suffield using a medium-scale flat target plate [35]; water- and air-filled ring-stiffened cylinder targets [36]; air-backed and water-backed small scale circular target plates subjected to near-contact explosions [37]; and smallscale square target plates of varying thickness and material [23]. Lee et al. [22] also experimentally simulated the

\footnotetext{
*Corresponding author. Tel.: +1 902426 3100; ext, 358; Fax: +1 902426 9654; E-mail: mark.riley@ drdc-rddc.gc.ca.
} 
effect of an explosion near a rigid boundary by simultaneously detonating twin horizontally separated charges. Other experimental studies include Brett and Yiannakopolous [2], who measured close-proximity loads and damage on unstiffened steel cylinders; van Aanhold and Bosman [1], who measured loads on a thick plate target subjected to close-proximity underwater explosion loading; and Menon [27], who conducted underwater explosion experiments near a rigid boundary by igniting a fuel and oxidizer mixture within a glass globe.

Several numerical studies have appeared that examine the interaction between the explosive gas bubble and a close proximity structure. Gibson and Blake [8] studied the dynamics of the gas bubble formation and collapse near deformable structures. Kalumuck et al. [13] studied the dynamics of the gas bubble in the presence of fixed rigid, moving rigid and deformable targets, finding that the bubble period for a flexible structure is shortened more than a moving rigid target relative to a fixed rigid target. No free field simulations or experiments were conducted to determine the influence of the fixed rigid structure on the bubble period. Wardlaw and Luton [39] looked at the interaction between the gas bubble and the shock wave for a close proximity target, including the development and the location of the cavitation region that was formed.

Numerical studies of the structural response or loading from gas bubble collapse include Kan et al. [14], who performed a two-fluid computational fluid dynamics study using JAYCOR's EITACC software to predict the first bubble collapse pressure on a submersed circular flat plate with a small explosive charge placed directly below the target. They found that the calculations overshoot measured jet impact peak pressures, but the general shape of the time histories agree reasonably well with experiments.

Klaseboer et al. [17] investigated several cases of gas bubble formation and collapse using a three-dimensional bubble dynamics code based on the boundary element method (BEM). They considered explosions under free-field conditions, near a vertical rigid target, and below a resilient horizontal target. For the free-field and charges near a vertical rigid target, only the bubble dynamics were studied. For the resilient target, the calculations were performed with a BEM code coupled to the structural finite element code PAM-CRASH ${ }^{T M}$. They found that the numerical simulations underestimated the bubble collapse period. The presence of the target was found to increase the bubble period by 5-10 percent over the free field condition. For the resilient structure, the target plate center displacement and some free-field pressure time histories for the numerical simulations were compared to experimental results. They found that their target displacement was underestimated by the numerical simulations, but had a final displacement within 15 percent of the experimental value. The second bubble collapse free-field pressure predictions showed reasonable agreement with the experiments, having magnitudes within 15 percent and pulse arrival times within 1.5 percent.

Free-field gas bubble behaviour can often be adequately predicted using analytical models, which are then useful for validating purely numerical solutions. The first analytical equation of motion (EOM) describing the gas bubble dilatation was derived by Lamb [19] based on an incompressible fluid. This was followed by studies by Taylor [38] and Shiffman and Friedman [33] who developed models coupling the dilatation and migration motions of the gas bubble based on an incompressible fluid. More realistic models include the effect of compressibility of the surrounding fluid. To include this effect, the sonic velocity of the surrounding fluid is introduced into the incompressible fluid models. Early models including fluid compressibility were developed by Herring [10], Kirkwood and Bethe [16], and Keller and Kolodner [15]. Currently the most popular analytical model is that proposed by Geers and Hunter [7,11] which uses a dilatational equation of motion based on the doubly asymptotic approximation. They also proposed a form of initial conditions for the bubble oscillation phase which bypasses the complexities of the shock phase. Although several approaches are available there are limitations in the predictive models. Like the similitude equations, current analytical models do not predict the influence of a close proximity target.

The present study focuses on bubble formation and collapse due to the detonation of a high explosive, Composition 4 (C4), at various standoffs and charge sizes. It compares the results of an extensive numerical study conducted using the CFD code Chinook with measurements from a series of close-proximity underwater explosion tests conducted at FOI Grindsjön, using a rigid target plate. The accuracy of the Chinook code in predicting the gas bubble behaviour and collapse loading in close-proximity to a rigid target, using two-dimensional and three-dimensional models of the explosion process is determined. Two approaches are used for three-dimensional analyses: direct analysis in three-dimensions; and a mapping method in which a refined two-dimensional analysis of the early shock phase is mapped onto a three-dimensional analysis domain and is used as an initial condition for the remainder of the three-dimensional analysis. The accuracy and efficiency of each approach is evaluated. New analytical dilatation 
and migration EOMs, developed by TNO and based on the Geers-Hunter model, were implemented in this study. Also included in this study is a new analytical approach based on a hemispherical gas bubble model developed by TNO to account for close-proximity targets. The Chinook gas bubble radii time histories are compared to empirical and analytical models. The accuracy of the simulations based on charge size and initial standoff are determined.

\section{Empirical and analytical gas bubble models}

\subsection{Empirical models}

The peak pressure and decay of the primary shock wave follow the forms of the similitude equations given in Eqs (1) and (2) [40].

$$
\begin{aligned}
& p_{0}=55.035\left(\frac{W_{C 4}^{1 / 3}}{R}\right)^{1.243} \\
& \theta=93.806 \cdot W_{C 4}^{1 / 3}\left(\frac{W_{C 4}^{1 / 3}}{R}\right)^{-0.230}
\end{aligned}
$$

Where $p_{0}$ is the peak pressure in MPa, $\theta$ is the decay constant in microseconds, $W_{C 4}$ the charge weight of Composition $4, \mathrm{C} 4$, in kilograms and $R$ is the radial standoff in meters. Similarly, the maximum gas bubble radius is estimated from [11]:

$$
R_{\max }=3.633\left(\frac{W_{C 4}}{D+10}\right)^{1 / 3}
$$

Where $R_{\max }$ is the maximum radius in meters and $D$ is the charge depth in meters. The bubble period $T_{b}$ in seconds is estimated by [11]:

$$
T_{b}=1.963 \frac{W_{C 4}^{1 / 3}}{(D+10)^{5 / 6}}
$$

The volume of the gas bubble can be reasonably approximated by the half sine function given by Eq. (5), where $V_{0}$ is the initial charge volume and $V_{\max }=\frac{4}{3} \pi R_{\max }^{3}$ is the maximum bubble volume.

$$
V(t)=V_{0}+\left(V_{\max }-V_{0}\right) \sin \left(\pi t / T_{b}\right)
$$

The radial time history is then determined using Eq. (6) based on assuming a spherical gas bubble.

$$
R(t)=\left(\frac{3}{4 \pi} V(t)\right)^{1 / 3}
$$

\subsection{Modified Geers-Hunter Analytical Bubble Model (TNO EOM)}

Based on the theory of the Geers-Hunter DA EOM, van Aanhold developed an analytical EOM for the dilatation and migration of the UNDEX gas bubble, as shown in Eq. (7) and (8), respectively:

$$
\begin{aligned}
& \left(\frac{3}{5} W+4 \pi \rho_{w} R^{3}\right) \ddot{R}=-6 \pi \rho_{w} R^{2} \dot{R}^{2}+K \pi \rho_{w} R^{2} \dot{z}^{2}+4 \pi R^{2}\left(\left(1+\frac{\dot{R}}{c_{l}} \frac{d}{d t}\right) P_{g}-p_{a i r}+\rho_{w} g z\right) \\
& \left(W+\frac{2}{3} \pi \rho_{w} R^{3}\right) \ddot{z}=\left(\frac{4}{3} \pi \rho_{w} R^{3}-W\right) g-2 \pi \rho_{w} R^{2} \dot{R} \dot{z}+\frac{\pi}{2} \rho_{w} C_{D} R^{2} \dot{z}|\dot{z}|
\end{aligned}
$$

Here $W$ is the charge weight, $\rho_{w}$ is the water density, $R$ is the gas bubble radius, $K$ is a kinetic energy coupling switch, $z$ is the bubble depth, $c_{l}$ is the sonic velocity of water, $P_{g}$ is the pressure of the gas inside the bubble, $p_{a i r}$ is the atmospheric air pressure, $g$ is the gravitational constant, $C_{D}$ is the drag constant, and dots above a symbol indicate differentiation with respect to time.

These equations differ from the Geers-Hunter DA EOM, in the following respects: 
- A kinetic energy coupling switch, $K$, is included which couples the kinetic energy of the dilatation motion to the migration motion. This can be turned off by setting $K=0$.

- The gas inertia effect in the dilatation and migration motions is included, as shown by the presence of the $W$ in the acceleration terms.

\subsection{Equation of state}

An equation of state is used to calculate the pressure within the gas bubble throughout the growth and collapse cycles. An adiabatic equation of state (EOS) is preferable for its simpler calculations. Development of adiabatic EOS for dense gas were carried out by Jones and Miller (JM EOS) [18] whose work was extended by Lee, Horning, and Kury (JWL EOS) [21]. Both forms produce consistent models for the adiabatic expansion of the gas bubble for densities in the range of $1.0-1.63 \mathrm{~g} / \mathrm{cm}^{3}$ and at pressures below $100 \mathrm{MPa}$. For these conditions the EOS can be simplified to the ideal-gas form given by Eq. (9), which is used in the present study instead of the more advanced JM and JWL EOS.

$$
P_{g}=\lambda K\left(\frac{V_{c}}{V_{g}}\right)^{\gamma}=\lambda K\left(\frac{R_{c}}{R_{g}}\right)^{3 \gamma}
$$

Here $P$ is the pressure within the gas bubble, $\lambda$ is the energy loss function as described in the next section, $K$ is the adiabatic charge constant, $V$ is the bubble volume, $R$ is the bubble radius, $\gamma$ is the constant ratio of specific heats, subscript $g$ denotes the gas bubble, and subscript $c$ denotes the initial charge.

The initial conditions used in this study were zero initial velocity and acceleration, and a gas bubble radius equal to the charge radius. The EOS constants, $K$ and $\gamma$, were determined by fitting the ideal gas EOS to the tail end of the adiabatic expansion produced by Cheetah's BKW-c EOS [6]. These are applicable to an incompressible fluid. For the compressible fluid adiabatic charge constant, Eq. (10) was used, where $p_{0}$ is the adiabatic charge constant, $\gamma$ is the ratio of specific heats determined from the Cheetah fit, $\rho_{x}$ is the charge density, and $h_{x}$ is the specific energy of the explosive.

$$
p_{0}=\frac{\gamma-1}{\gamma} \rho_{x} h_{x}
$$

The resulting $K$ and $\gamma$ for the compressible gas where found to be $1950 \mathrm{MPa}$ and 1.288 respectively.

\subsection{Energy loss model}

An energy loss function is introduced in order to account for losses in the gas bubble radius and period for cycles after the first bubble collapse. The approach implemented in this study uses the first cycle gas bubble constants in conjunction with an energy loss function to determine the radial time histories. The energy loss function, given by Eq. (11), derived from the reduction values discussed by Geers and Hunter [7,11].

$$
\lambda=0.2575+(1-0.2575) \exp (-0.8148 m), \quad m=0,1,2, \ldots
$$

Here $\lambda$ has an initial value of $1(m=0)$, and $m$ is the cycle number starting at 0 for detonation and with $m=1$ for the first gas bubble minimum. The energy loss function is implemented by reducing the charge weight at each gas bubble minimum, such that the new charge weight is $\lambda W$. This new charge weight is input into Eqs (3) and (4) to determine the maximum gas bubble radius and bubble period for the next cycle, resulting in a decrease in the maximum gas bubble radius and periods by a factor of $\lambda^{1 / 3}$.

\subsection{Close-proximity hemispherical bubble model}

The simplest gas bubble model for close-proximity UNDEX is a hemispherical gas bubble which is centered on the rigid target, as shown by Fig. 1 . 


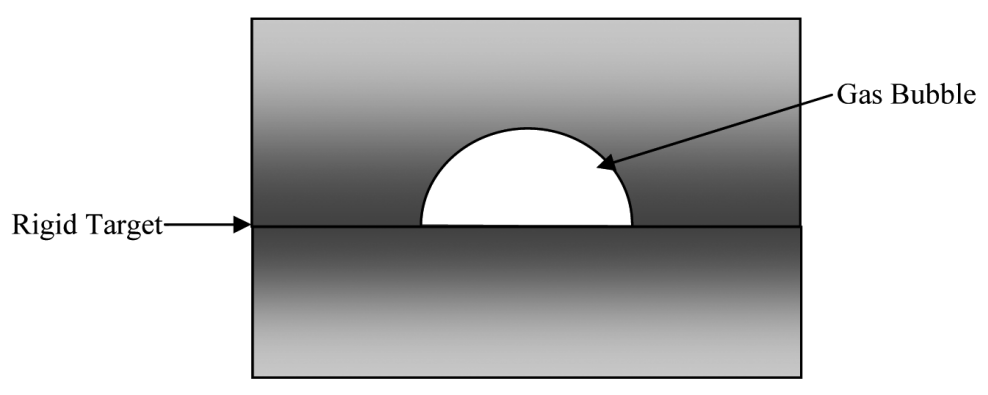

Fig. 1. Hemispherical gas bubble.

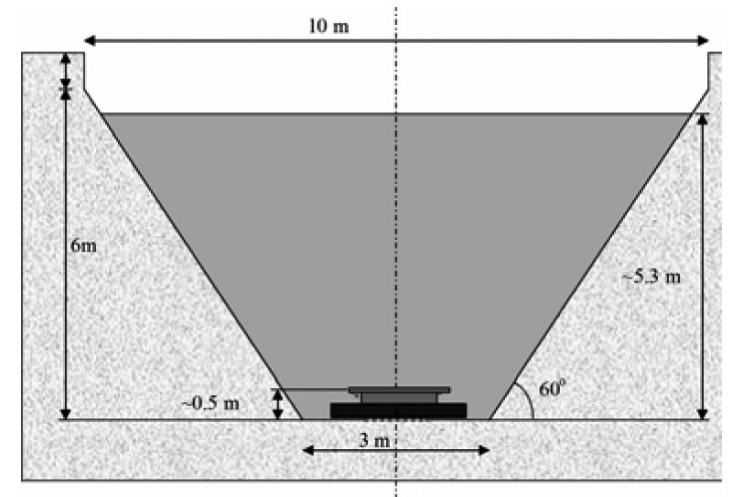

(a)

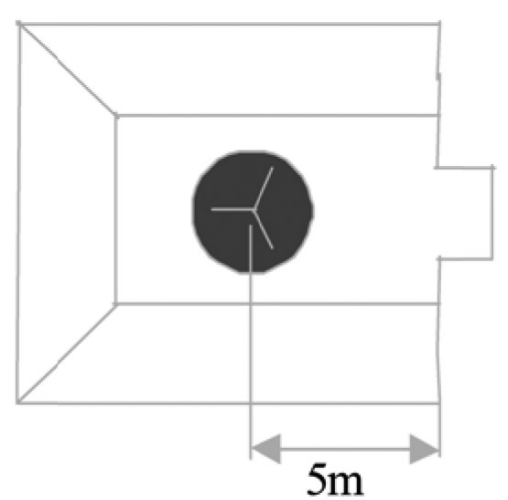

(b)

Fig. 2. Test basin facility at FOI Grindsjön (a) cross-section view, (b) top view.

In this model the rigid surface coincides with the gas bubbles symmetry plane and has no influence on the radial fluid motion. The behaviour of the hemispherical gas bubble caused by a hemispherical charge of mass, $W$, is therefore the same as a spherical gas bubble with migration suppressed and a spherical charge mass of $2 W$. Using this methodology the gas bubble expansion and collapse can be described with the similitude and analytical gas bubble models.

The equivalent radius, $R_{e q}$, of a spherical gas bubble with the same volume as the hemispherical gas bubble is given by Eq. (12), where $R$ is the actual radius of the hemispherical gas bubble.

$$
R_{e q}=\frac{R}{2^{1 / 3}}
$$

Doubling the charge weight increases the gas bubble period by 1.26 times, as shown by Eq. (13).

$$
T_{b}=1.963 \cdot \frac{\left(2 W_{C 4}\right)^{1 / 3}}{(D+10)^{5 / 6}}=2.473 \cdot \frac{W_{C 4}^{1 / 3}}{(D+10)^{5 / 6}}
$$

\section{Experimental investigation}

The experiments used for this study were conducted at FOI Grindsjön, Sweden, in 2007. The test set-up is a modified version as outlined by van Aanhold and Bosman [1]. The test basin, shown in Fig. 2 , is $10 \times 14 \mathrm{~m}^{2}$ at the top and $6 \mathrm{~m}$ deep. As Fig. 2 shows, three of the sides are sloped at $60^{\circ}$ to reflect the shock waves away from the target. The fourth side is a flat wall with a recess for conducting air-backed experiments. The walls are made of $\sim 0.5 \mathrm{~m}$ thick armoured concrete which was cast directly onto the base rock.

The rigid plate was positioned approximately at the center of the bottom surface of the basin. The depth of the water above the plate surface was measured to be approximately $5 \mathrm{~m}$ at the time of the experiments. The target plate, 
Table 1

Test set-up for rigid plate experiments conducted at FOI Grindsjön

\begin{tabular}{ccc}
\hline Case & Charge size $(\mathrm{g})$ & Standoff $(\mathrm{m})$ \\
\hline A1 & 40 & 0.30 \\
A2 & 40 & 0.51 \\
A3 & 40 & 0.77 \\
B1 & 200 & 0.52 \\
\hline
\end{tabular}

Table 2

Equation of state properties for the Chinook Analyses

\begin{tabular}{|c|c|c|c|c|c|}
\hline \multicolumn{2}{|c|}{ JWL parameters for $\mathrm{C} 4$} & \multicolumn{2}{|c|}{ Tait parameters for water } & \multicolumn{2}{|c|}{ Ideal gas parameters for air } \\
\hline $\mathrm{A}(\mathrm{Pa})$ & $609.8 \times 10^{9}$ & Density $\left(\mathrm{kg} / \mathrm{m}^{3}\right)$ & 1000 & Gamma & 1.4 \\
\hline $\mathrm{B}(\mathrm{Pa})$ & $12.95 \times 10^{9}$ & $\mathrm{~B}$ & 3000 & & \\
\hline $\mathrm{C}(\mathrm{Pa})$ & $1.034 \times 10^{9}$ & $\mathrm{~N}$ & 7.14 & Density $\left(\mathrm{kg} / \mathrm{m}^{3}\right)$ & 1.177 \\
\hline $\mathrm{R} 1$ & 4.50 & M & 5.000 & & \\
\hline $\mathrm{R} 2$ & 1.40 & Reference surface pressure $(\mathrm{kPa})$ & 101.3 & Molar Weight & 28.97 \\
\hline$\omega$ & 0.25 & & & & \\
\hline
\end{tabular}

shown in Fig. 3(a), is $1.5 \mathrm{~m}$ in diameter and $50 \mathrm{~mm}$ thick. Two H-beams were welded to the bottom of the bottom plate to act as lifting devices. The plate was instrumented with a total of 33 pressure measurement gauges, with the positioning as shown in Fig. 3(b). The gauges were mounted to withstand the shock loading from the explosion as well as the fluid flow from the bubble expansion and collapse. The types of measurement systems included tourmaline piezoelectric gauges (P01...P08, C01 and C02, F01...F03), Kulite piezo-resistive gauges (K01 and $\mathrm{K} 02$ ), and steel rod gauges (S1A, S1B, S02 . . S17). During the test program no measurement gauges were removed or replaced.

The experiments from the test series that were modeled for the present study are shown in Table 1.

\section{Numerical analysis}

The numerical modelling for this study was conducted using Chinook, a computational fluid dynamics code developed by Martec Ltd [26] specifically designed for modeling explosions, which is based on the Euler inviscid fluid dynamics equations (i.e. conservation of mass, momentum, and energy). The solver within Chinook uses explicit time stepping with either a single-step, 2-step Euler, or 4-stage Runge-Kutta approach. The fluxes are computed using an inviscid high speed convection scheme based on the HLLC approximate Riemann solver. Second order special accuracy is achieved using a flux limiting scheme on unstructured meshes. The time step is determined based on the time for a transient wave to progress through an element.

\subsection{Material modelling}

Equations of states (EOS) are used to define the pressure as a function of density for each of the materials. The Jones-Wilkens-Lee (JWL) EOS was used for C4, the Tait EOS for water, and the ideal gas EOS for air. The EOS parameter values and other properties for $\mathrm{C} 4$ were provided by FOI, whereas those used for water and air are generally accepted values. The numerical values used are summarized in Table 2.

\subsection{Modeling approach}

The numerical analyses used two-dimensional models with different mesh densities; three-dimensional models for direct simulations from the explosive detonation; and three-dimensional models in which the initial shock propagation phase of the loading is mapped from refined two-dimensional analyses. For all analyses, the rigid target plate was modeled with a fixed boundary having similar geometry as the target plate. 


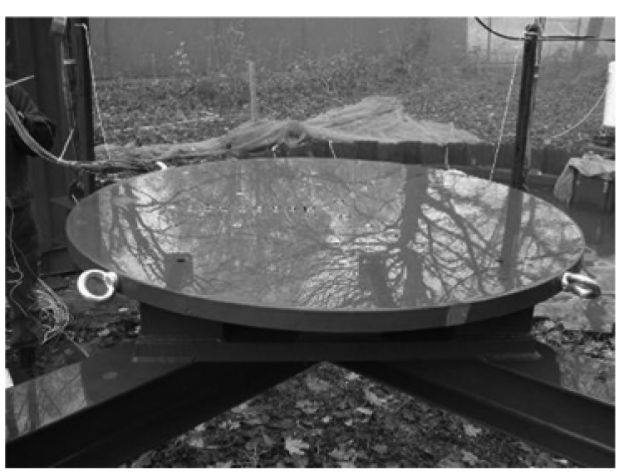

(a)

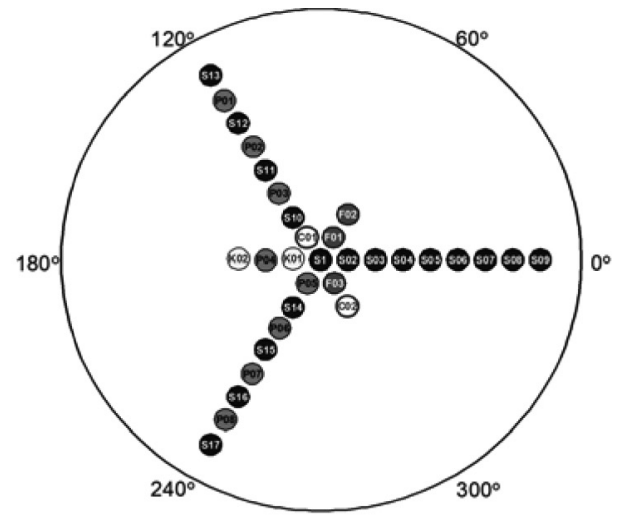

(b)

Fig. 3. Target plate used for experiments (a) experimental target plate, (b) location of pressure measurement gauges/systems [1].

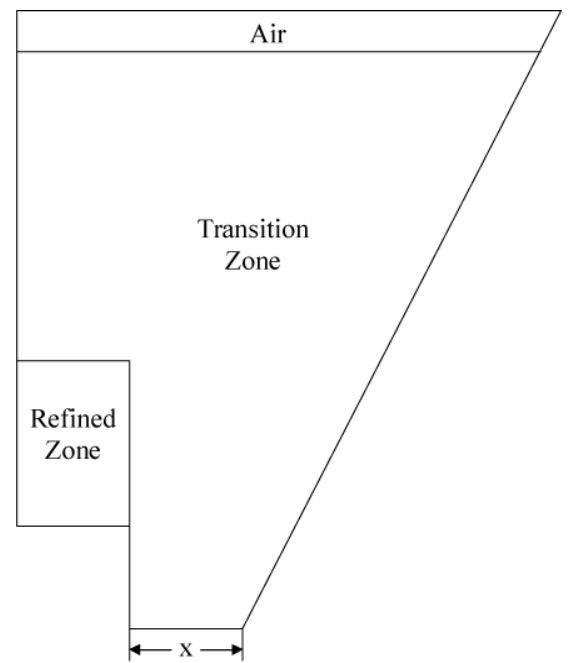

(a)

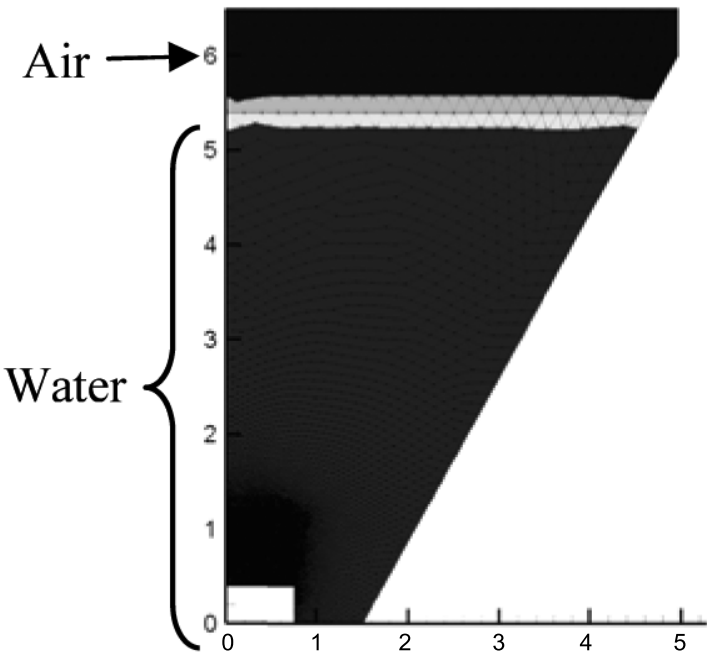

(b)

Fig. 4. Two-dimensional domain used to model the testing basin at FOI Grindsjön (a) Geometric domain (b) Example of a coarse two-dimensional mesh.

\subsection{Two-dimensional mesh development}

Although the basin is not axisymmetric, considerable benefit is derived from an axisymmetric modelling approach because of the time savings gained by two-dimensional versus a three-dimensional analysis. Figure 4 shows the general domain shape and the coarse mesh used for the two-dimensional models. The domain size of the twodimensional models is controlled by the dimension $x$ in Fig. 4(a). For the smaller dimension of the basin $x=$ $750 \mathrm{~mm}$, while for the larger dimension $x=1500 \mathrm{~mm}$. Because the Eulerian grids used by Chinook do not clearly delineate the air and water, the white band at the water/air interface is a region where a mixture of water and air exist.

All two-dimensional meshes were created using an unstructured grid of triangular cells, which in Chinook produce a better bubble shape than structured meshes of square cells. Table 3 shows the mesh densities used for the various two-dimensional models, where C, R1, R2, and R3 refer to the coarse model and the refined models of progressively increasing degree of refinement. The number of cells in these models ranged from 22,115 for the coarse mesh to 183,312 cells for the R3 mesh. 
Table 3

Refined zone size and mesh densities used for two-dimensional analyses

\begin{tabular}{|c|c|c|c|c|c|c|c|}
\hline \multirow[t]{2}{*}{ Simulation case } & \multicolumn{2}{|c|}{ Refined zone dimensions } & \multicolumn{4}{|c|}{ Refined zone cell size $(\mathrm{mm})$} & \multirow{2}{*}{$\begin{array}{l}\text { Transition zone cell } \\
\text { size }(\mathrm{mm})\end{array}$} \\
\hline & Height $(\mathrm{mm})$ & width $(\mathrm{mm})$ & $\mathrm{C}$ & R1 & R2 & R3 & \\
\hline $40 \mathrm{~g}$ at $0.6 \mathrm{R}$ & 800 & 750 & 10 & 7.5 & 5 & 3 & Gradually increased \\
\hline $40 \mathrm{~g}$ at $1.0 \mathrm{R}$ & 1100 & & & & & & up to $300 \mathrm{~mm}$ at the \\
\hline $40 \mathrm{~g}$ at $1.5 \mathrm{R}$ & 1300 & & & & & & outer boundaries \\
\hline $200 \mathrm{~g}$ at $0.6 \mathrm{R}$ & 1400 & 900 & & & & & \\
\hline
\end{tabular}

Table 4

Refined zone dimensions and mesh densities for the three-dimensional models

\begin{tabular}{lllc}
\hline Model & Refined zone cell size & Transition zone & Number of cells (million) \\
\hline $40 \mathrm{~g}$ at $0.6 \mathrm{R}$ mapped & $10 \mathrm{~mm}$ for all models & $10-300 \mathrm{~mm}$ & 1.87 \\
$40 \mathrm{~g}$ at $1.0 \mathrm{R}$ mapped & & & 1.97 \\
$40 \mathrm{~g}$ at $1.5 \mathrm{R}$ mapped & & & 2.37 \\
$200 \mathrm{~g}$ at $0.6 \mathrm{R}$ mapped & $20 \mathrm{~mm}$ & $20-300 \mathrm{~mm}$ & 1.81 \\
$200 \mathrm{~g}$ at $0.6 \mathrm{R}$ 3D coarse* & $7.5-25 \mathrm{~mm}$ & $25-250 \mathrm{~mm}$ & 0.70 \\
$200 \mathrm{~g}$ at $0.6 \mathrm{R}$ 3D refined* & $5.2-20 \mathrm{~mm}$ & $20-250 \mathrm{~mm}$ & 1.41 \\
\hline
\end{tabular}

*indicates the models that included the charge (Hypermesh models).

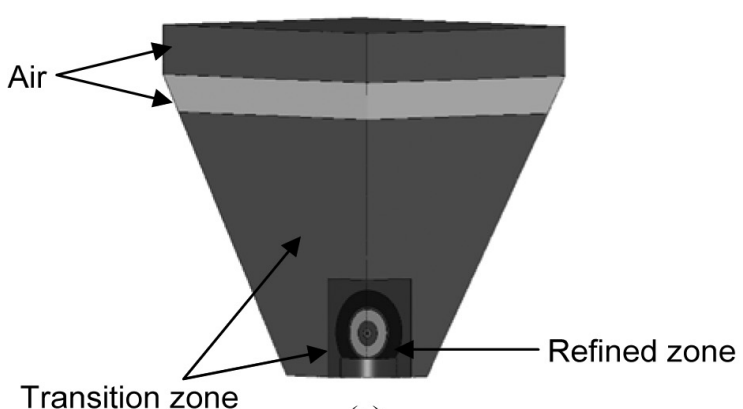

(a)

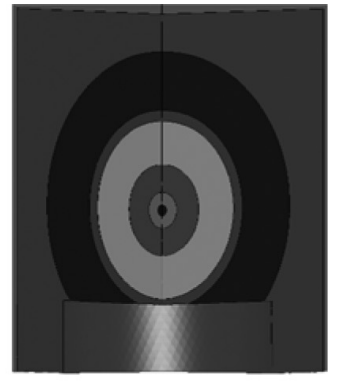

(b)

Fig. 5. Three-dimensional domain used for the test basin at FOI Grindsjön for 3D analysis including the explosive in the analysis (a) full domain (b) refined zone (bubble contained within the outer black region).

\subsection{Three-dimensional mesh development}

Although the test basin has only one plane of symmetry, quarter models of the fluid domain are used with two symmetry planes. These models are based on the upper left quadrant in Fig. 2(b) and contain two sloping sides of the basin. This assumption reduces the computational cost of the three-dimensional simulations while still providing a good approximation of the fluid domain. Two different meshing methods are followed according to the type of 3D simulation. For simulations beginning from detonation, meshing is based on the geometry of Fig. 5, with additional refinement close to the charge. Figure 5(b) shows the structure within the refined zone, which encompasses the bubble at maximum expansion, and is where the mesh density is controlled. The small black volume at the center contains the charge. The transition zone is comprised of all regions outside the refined zone in Fig. 5(a).

With the mapping method, a uniform fluid mesh is used throughout the volume where the bubble forms, (i.e. the refined zone). A three-dimensional mesh refinement study performed for a different geometry [4,5] found that a cell size of $12 \mathrm{~mm}$ in the refined zone gave results for a $40 \mathrm{~g} \mathrm{C} 4$ charge that were comparable to those for a three-dimensional analysis starting from detonation. Figure 6 shows the geometric model used to create the fluid domain mesh used for the mapped approach.

The cell size in the refined zone varied from $10 \mathrm{~mm}$ to $25 \mathrm{~mm}$ depending on the experiment that was being simulated. The dimensions of the refined zone were chosen to ensure they were larger than the maximum bubble radius. Unstructured grids of tetrahedral cells were used for the entire fluid domain and the charge. The mesh densities for all the three-dimensional models are shown in Table 4. 
Table 5

Average bubble periods for the different two-dimensional domain sizes and mesh densities for the $40 \mathrm{~g} \mathrm{C} 4$ charge at a standoff of $0.6 \mathrm{R}$

\begin{tabular}{|c|c|c|c|c|c|c|c|c|}
\hline \multirow[t]{2}{*}{$\begin{array}{c}\text { Bubble } \\
\text { collapse event }\end{array}$} & \multirow[t]{2}{*}{$\begin{array}{c}\text { Experimental } \\
\text { bubble period (ms) }\end{array}$} & \multicolumn{4}{|c|}{$\begin{array}{l}\text { Small domain model } \\
\text { bubble periods (ms) }\end{array}$} & \multicolumn{3}{|c|}{$\begin{array}{l}\text { Large domain model } \\
\text { bubble periods (ms) }\end{array}$} \\
\hline & & $\mathrm{C}$ & $\mathrm{R} 1$ & $\mathrm{R} 2$ & R3 & $\mathrm{R} 1$ & R2 & R3 \\
\hline First & 88.6 & 91.5 & 92.0 & 92.6 & 93.3 & 87.9 & 88.4 & 89.1 \\
\hline Second & 57.7 & 64.2 & 64.8 & 65.5 & 66.8 & 62.2 & 63.2 & 64.1 \\
\hline
\end{tabular}

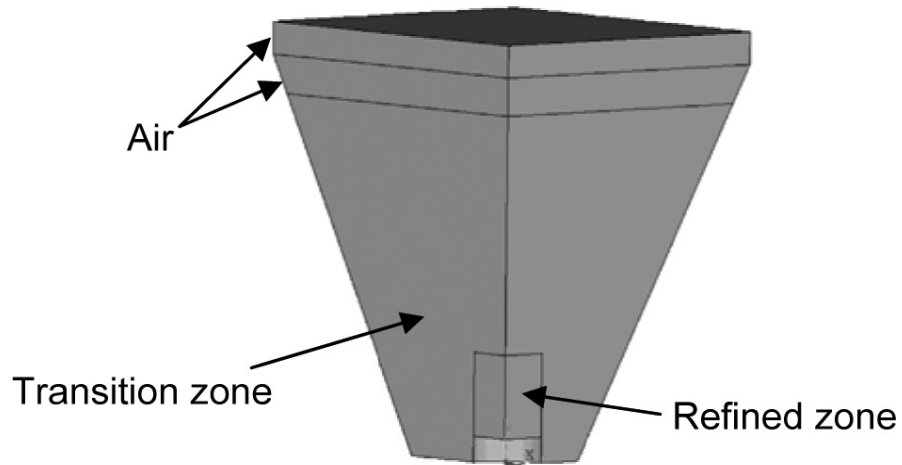

Fig. 6. Three-dimensional domain used for the test basin at FOI Grindsjön in conjunction with the 2D mapping technique.

\section{Results}

\subsection{Influence of two-dimensional model domain}

The gas bubble period and collapse impulse loading for the small domain (SD) and large domain (LD) twodimensional models are shown in Table 5 and Fig. 7, respectively.

Table 5 shows that for models with the same mesh refinement, the small domain models have a first and second bubble period approximately $5 \%$ and $4 \%$ larger, respectively, than the large domain models. The domain size also has a slight effect on the impulse loading, varying up to approximately $4 \%$ for the first and second bubble collapse as shown in Fig. 7. Unlike the bubble period, the impulse loading is not always larger than the experiments and sometimes varies considerably from gauge to gauge. As the mesh is refined further, the bubble period and impulse loading both increase, and generally diverge from the experimental measurements. After conducting these analyses it was found that the cut off pressure used to model cavitation can influence the time scale of the bubble collapse [3]. This affects the bubble behaviour because at the bubble's maximum bubble radii, the bubble pressure is very close to the cut off pressure. Currently, the cut-off pressure for controlling cavitation is an internal parameter in Chinook, and cannot be changed by the user. This has been corrected in the upcoming Chinook release. The same patterns were observed for all charge sizes and standoffs; therefore only typical two-dimensional results will be shown in later sections.

\subsection{Gas bubble radius and period}

Examples of the gas bubble radius time histories for the free field (FF) similitude and analytical models, close proximity (CP) similitude and analytical models, Chinook 2D simulations, and experimental bubble periods are shown in Fig. 8. Comparison of the experimental and FF similitude pulse arrival times shows that periods of the first bubble collapse increase as the bubble moves closer to the target. This increase in period is shown in experiments to be related to reductions in pressure loading on the bubble surface close to the target interface, which in turn permit greater expansion and slower oscillation of the bubble [24].

Table 6 summarizes the measured and predicted first bubble periods for all methods. It shows that gas bubble periods predicted by Chinook are in better agreement with the experiments than are those predicted by the analytical 
Table 6

Average first bubble periods for the different modeling approaches and from experiments

\begin{tabular}{|c|c|c|c|c|c|c|c|c|}
\hline \multirow[t]{2}{*}{ Test case } & \multirow[t]{2}{*}{$\begin{array}{c}\text { Experimental } \\
\text { bubble period (ms) }\end{array}$} & \multicolumn{2}{|c|}{$\begin{array}{l}\text { Empirical bubble } \\
\text { periods (ms) }\end{array}$} & \multicolumn{2}{|c|}{$\begin{array}{c}\text { Analytical bubble } \\
\text { periods }(\mathrm{ms})\end{array}$} & \multicolumn{3}{|c|}{$\begin{array}{c}\text { Numerical bubble } \\
\text { periods }(\mathrm{ms})\end{array}$} \\
\hline & & FF & $\mathrm{CP}$ & FF & $\mathrm{CP}$ & $2 \mathrm{D}$ & 3D Map & 3D Full \\
\hline $40 \mathrm{~g}$ at $0.6 \mathrm{R}$ & 89.1 & 76.7 & 95.1 & 77.8 & 96.3 & 88.5 & 85.3 & N/A \\
\hline $40 \mathrm{~g}$ at $1.0 \mathrm{R}$ & 88.4 & 76.7 & 95.1 & 77.8 & 96.3 & 86.0 & 83.1 & N/A \\
\hline $40 \mathrm{~g}$ at $1.5 \mathrm{R}$ & 85.1 & 76.7 & 95.1 & 77.8 & 96.3 & 83.5 & 84.0 & N/A \\
\hline $200 \mathrm{~g}$ at $0.6 \mathrm{R}$ & 155.2 & 132.9 & 162.7 & 135.3 & 164.7 & 151.2 & 151.3 & 151.1 \\
\hline
\end{tabular}

Table 7

Average second bubble periods for the different modeling approaches and from experiments

\begin{tabular}{|c|c|c|c|c|c|c|c|c|}
\hline \multirow[t]{2}{*}{ Test case } & \multirow[t]{2}{*}{$\begin{array}{c}\text { Experimental } \\
\text { bubble period (ms) }\end{array}$} & \multicolumn{2}{|c|}{$\begin{array}{l}\text { Empirical bubble } \\
\text { periods }(\mathrm{ms})\end{array}$} & \multicolumn{2}{|c|}{$\begin{array}{l}\text { Analytical bubble } \\
\text { periods }(\mathrm{ms})\end{array}$} & \multicolumn{3}{|c|}{$\begin{array}{c}\text { Numerical bubble } \\
\text { periods }(\mathrm{ms})\end{array}$} \\
\hline & & $\mathrm{FF}$ & $\mathrm{CP}$ & $\mathrm{FF}$ & $\mathrm{CP}$ & $2 \mathrm{D}$ & 3D Map & 3D Full \\
\hline $40 \mathrm{~g}$ at $0.6 \mathrm{R}$ & 57.7 & 64.9 & 80.4 & 59.5 & 72.8 & 64.4 & 59.6 & N/A \\
\hline $40 \mathrm{~g}$ at $1.0 \mathrm{R}$ & 65.2 & 65.7 & 80.4 & 60.4 & 72.8 & 73.6 & 65.9 & N/A \\
\hline $40 \mathrm{~g}$ at $1.5 \mathrm{R}$ & 62.6 & 66.7 & 80.4 & 61.3 & 72.8 & 66.2 & 62.9 & N/A \\
\hline $200 \mathrm{~g}$ at $0.6 \mathrm{R}$ & 102.8 & 113.8 & 139.0 & 104.0 & 123.3 & 112.0 & 102.9 & 104.3 \\
\hline
\end{tabular}

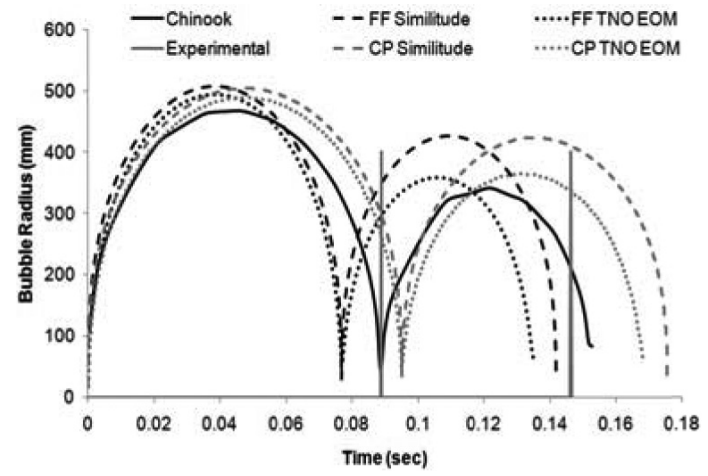

(a)

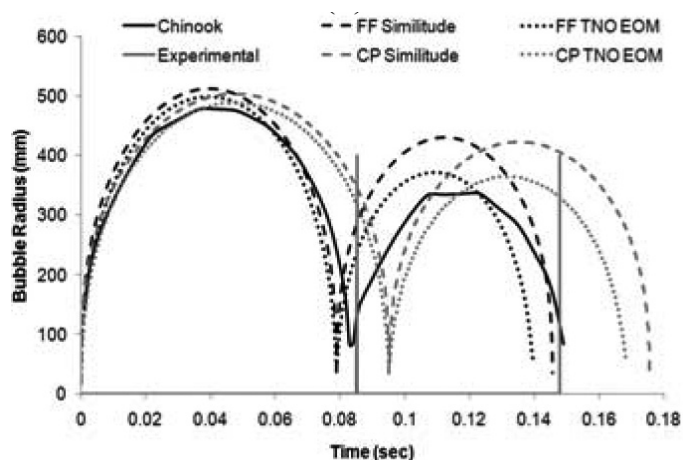

(c)

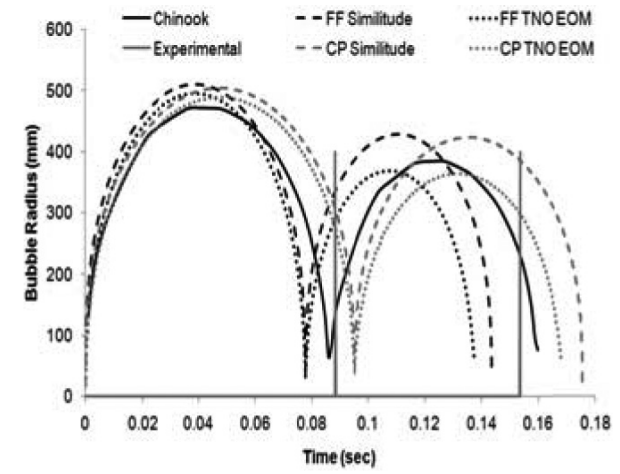

(b)

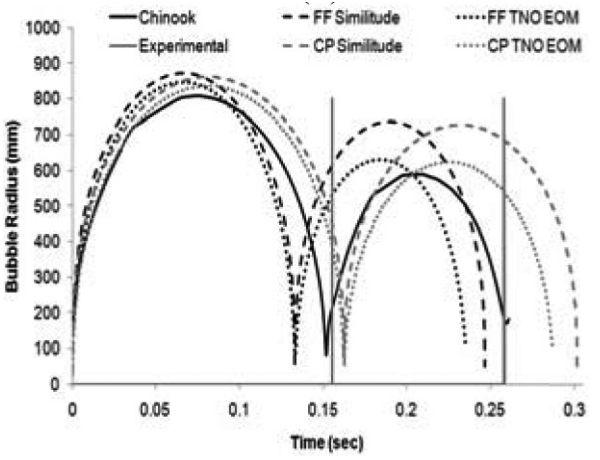

(d)

Fig. 7. Gas bubble radius time histories comparing numerical, analytical, empirical, and experimental approaches (a) $40 \mathrm{~g}$ C4 at $0.6 \mathrm{R}$, (b) $40 \mathrm{~g}$ $\mathrm{C} 4$ at $1.0 \mathrm{R}$, (c) $40 \mathrm{~g} \mathrm{C} 4$ at $1.5 \mathrm{R}$, (d) $200 \mathrm{~g} \mathrm{C} 4$ at $0.6 \mathrm{R}$.

and empirical models. The FF analytical and empirical methods typically under-predict the bubble period, whereas the corresponding CP methods somewhat overestimate it.

The second gas bubble periods are summarized in Table 7 for all cases. Here the two FF models are closer to the experiments than the two CP methods, which significantly over-predict the second gas bubble period. Here the energy reduction factor has been used in both the FF and CP methods. Table 6 and Fig. 8 together show that while 


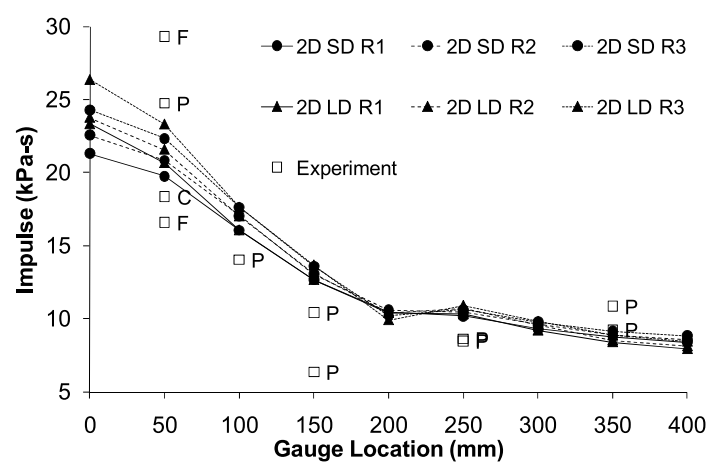

(a)

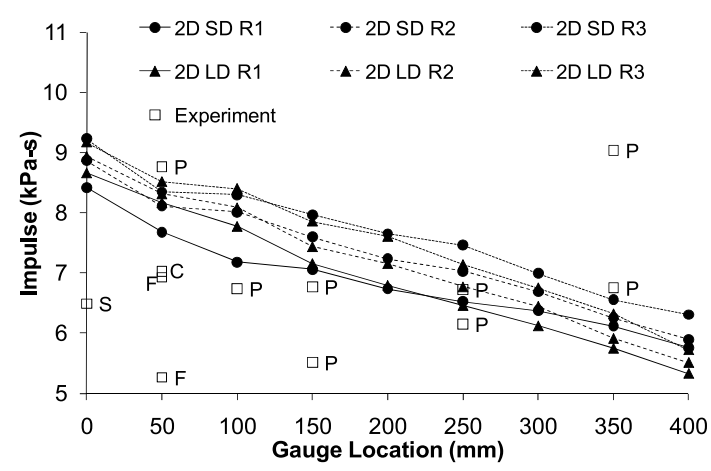

(b)

Fig. 8. Effect of the model domain size and mesh refinement on the two-dimensional numerical predictions for the $40 \mathrm{~g} \mathrm{C} 4$ charge at a standoff of $0.6 \mathrm{R}$ (a) first bubble collapse impulse (b) second bubble collapse impulse.

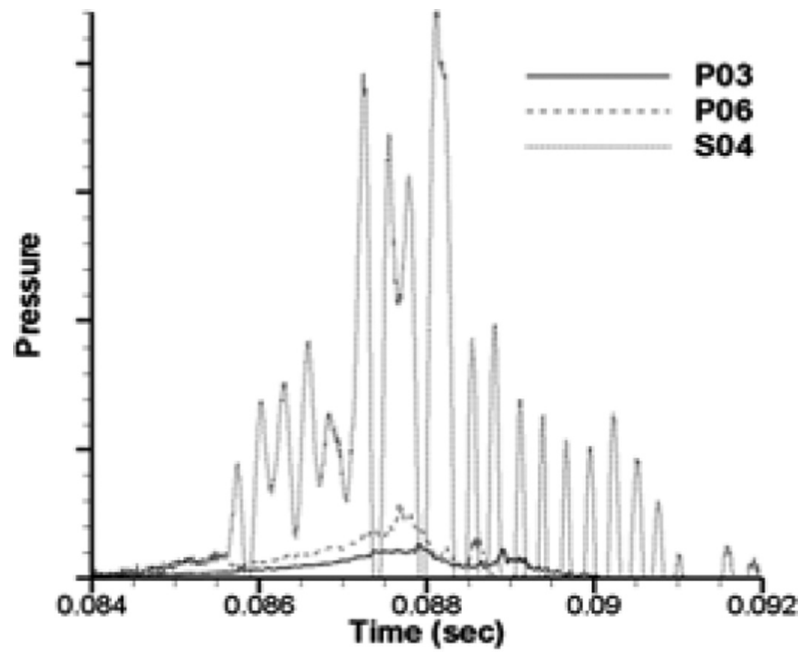

Fig. 9. Comparison of piezoelectric and steel rod pressure measurement gauges at the same radial position.

the first gas bubble period decreases with increasing initial standoff distance, the second bubble period is maximum at a standoff of $1.0 \mathrm{R}$ for the test cases considered in this study.

The maximum bubble radius predicted by Chinook is slightly smaller than those indicated by the similitude and analytical methods (see Fig. 8). Experimental results for the gas bubble periods are indicated in this figure as vertical lines. The actual gas bubble radii were not measured.

\subsection{Target loading}

The pressure measurements of the steel rod gauges were very oscillatory and in general did not produce results consistent with other gauges. This is shown in Fig. 9, where P03 and P06 are the piezoelectric pressure gauges and S04 is the steel rod gauge.

There was considerable variability in the results among steel rod gauges at the same radial position, and to a lesser extent among the piezoelectric gauges. For this reason the discussion of the pressure and impulse results is limited to those measured with the more reliable piezoelectric gauges. This provides some indication of the amount of error in the measurements. Other sources of discrepancy between gauges at the same radial position and different circumferential positions include the geometry of the basin, the embedding material used to encase the gauge, the gauge type, and the embedding arrangement. 


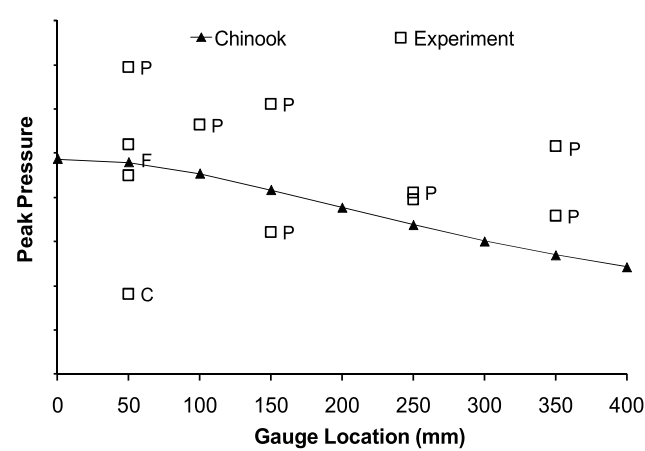

(a)

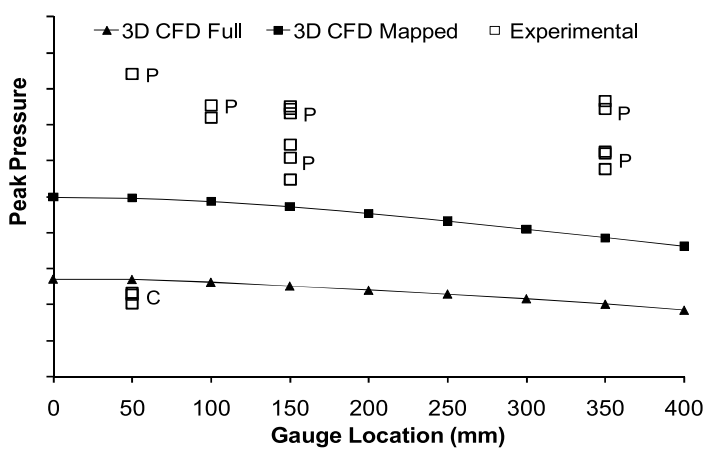

(b)

Fig. 10. Peak shock pressure for (a) $40 \mathrm{~g} \mathrm{C} 4$ charge at $0.6 \mathrm{R}$ (b) $200 \mathrm{~g} \mathrm{C} 4$ charge at $0.6 \mathrm{R}$.

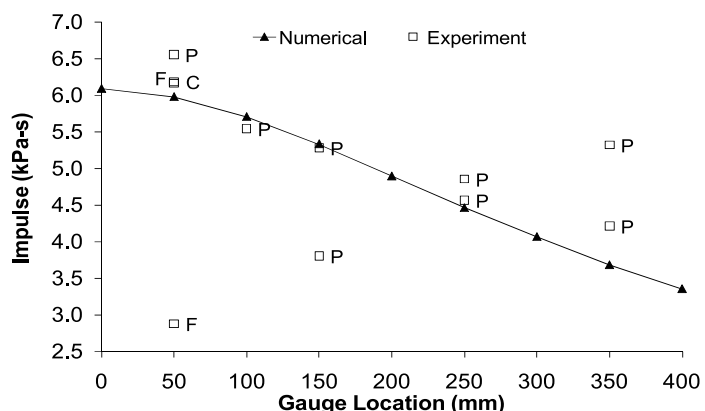

(a)

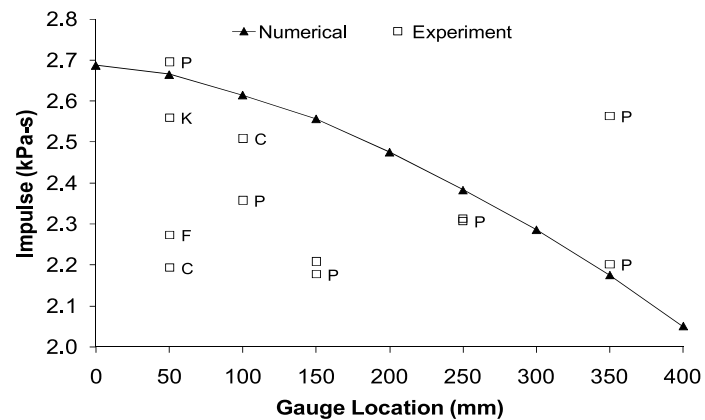

(c)

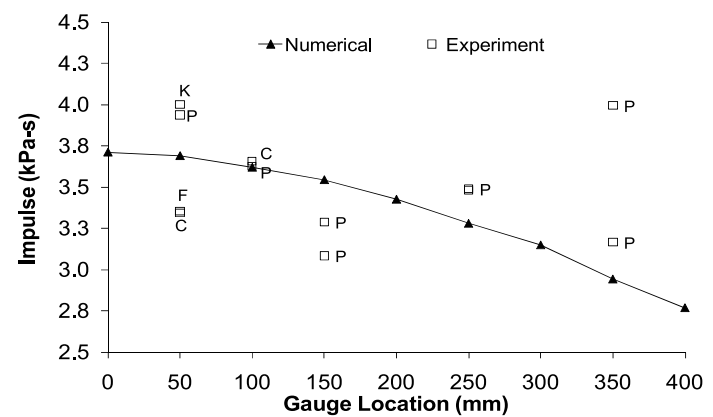

(b)

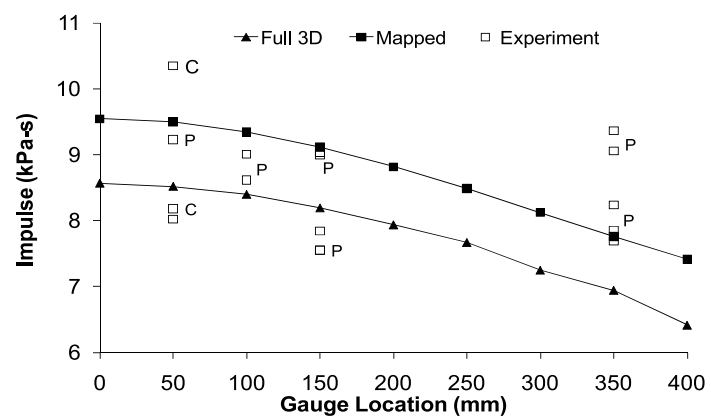

(d)

Fig. 11. Peak shock impulse for (a) $40 \mathrm{~g} \mathrm{C} 4$ charge at $0.6 \mathrm{R}$ (b) $40 \mathrm{~g} \mathrm{C} 4$ charge at $1.0 \mathrm{R}$ (c) $40 \mathrm{~g} \mathrm{C} 4$ charge at $1.5 \mathrm{R}$ (d) $200 \mathrm{~g} \mathrm{C} 4$ charge at $0.6 \mathrm{R}$.

\subsection{Shock loading}

Figures 10 and 11 show the shock pressures and impulse jumps for the experiments and Chinook analyses. The numerical value of the peak pressures are not shown due to data sensitivity. The letters beside the experimental points indicate the gauge type: $S$ for the steel rod gauges, $P$ and $C$ for the tourmaline piezoelectric gauges in cavities, $K$ for the Kulite piezo-resistive gauges, and $F$ for FOI's tourmaline piezoelectric gauges. Data points that are outside the ranges of the plots are not shown to avoid obscuring the main trends. Nevertheless, a large amount of scatter among the measurements is evident. The accuracy of shock measurements is affected by the physical size of the gauge in comparison to the width of the shock front, and by the embedding of gauges in cavities. 


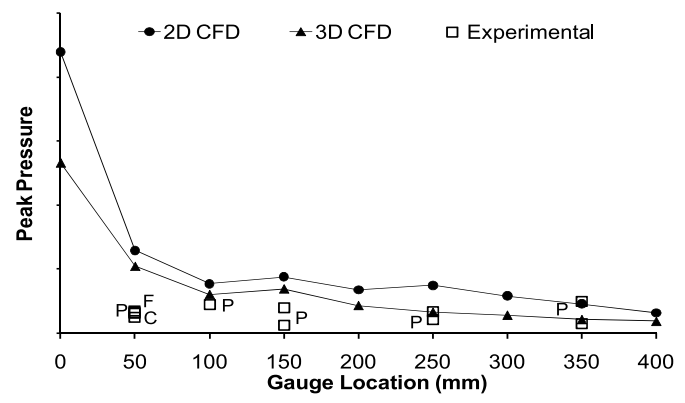

(a)

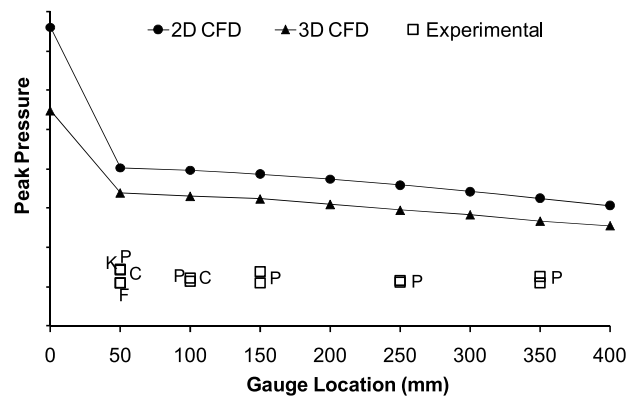

(c)

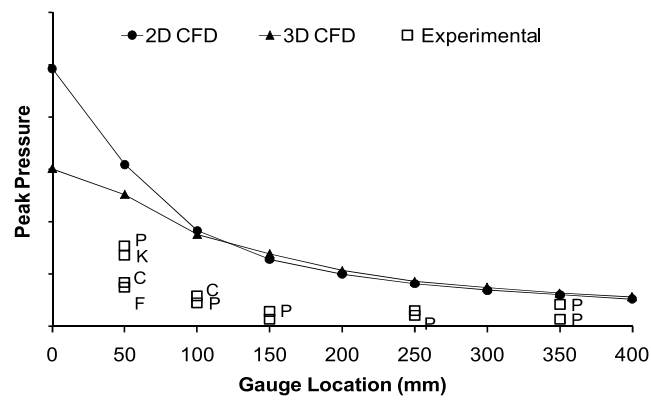

(b)

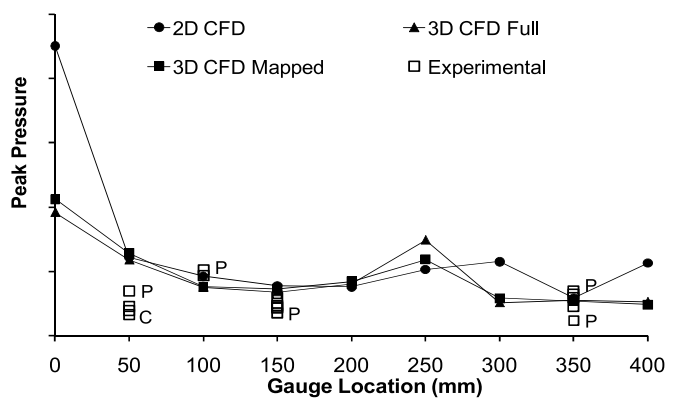

(d)

Fig. 12. Peak pressure associated with the first bubble collapse (a) $40 \mathrm{~g} \mathrm{C} 4$ charge at $0.6 \mathrm{R}$ (b) $40 \mathrm{~g} \mathrm{C} 4 \mathrm{charge}$ at $1.0 \mathrm{R}$ (c) $40 \mathrm{~g}$ C4 charge at $1.5 \mathrm{R}$ (d) $200 \mathrm{~g} \mathrm{C} 4$ charge at $0.6 \mathrm{R}$.

Figure 10 shows the Chinook peak shock pressures are generally within $12 \%$ of the experimental range for the $40 \mathrm{~g}$ charge at a standoff of $0.6 \mathrm{R}$. This difference increased up to $40 \%$ for the $40 \mathrm{~g}$ charge at a standoff of $1.5 \mathrm{R}$ (not shown). For the $200 \mathrm{~g} \mathrm{C} 4$ charge, the Chinook mapped approach underestimates the experimental measurements by $30 \%$, with the full three-dimensional analysis showing only half the magnitude of the mapped approach. The peak pressures predicted by Chinook and measured by the piezoelectric gauges show the expected slight decrease with increasing radial position. Figure 11 shows that the impulse predictions are in better agreement to the measured values, and usually lie within $5 \%$ of the range in the experimental piezoelectric gauge measurements.

\subsection{Bubble collapse loading}

Figures 12 and 13 show the experimental and numerical peak pressures and impulse jumps associated with the first bubble collapse. Similar to Fig. 10, the numerical values of the peak pressures are not shown due to classification sensitivity. The Chinook predictions overestimate the bubble collapse pressure when compared to the piezoelectric gauge measurements, and significantly under estimate the pressure loading compared to the steel rod gauges (not shown). The exception is the $200 \mathrm{~g} \mathrm{C} 4$ charge, where the numerical predictions are reasonably close to the piezoelectric measurements when the gauges are located $100 \mathrm{~mm}$ or further from the plate center. At the center of the plate, large pressure spikes are predicted as shown by the predictions at $0 \mathrm{~mm}$ in Fig. 12.

The width of the pressure spikes were determined from the radius at which the pressure drops to half of the peak value at the plate centre. The widths were determined to be as follows: three cells for the $40 \mathrm{~g}, 0.6 \mathrm{R}$ standoff; five cells for the $40 \mathrm{~g}, 1.0 \mathrm{R}$ standoff; and four cells for the $200 \mathrm{~g}, 0.6 \mathrm{R}$ standoff; and ten cells for the $200 \mathrm{~g}, 1.0 \mathrm{R}$ charge. The bubble impact pressure drops nearly $40 \%$ between the center of the plate and the $50 \mathrm{~mm}$ gauge location. Similar peak pressures were predicted for the second bubble collapse, but they were not as narrow as those observed for the first bubble collapse. Nonetheless, no experimental evidence for these localized peaks, possibly associated with the water jetting, has been observed. This could partly be attributed to the unreliable gauges used at the plate center in these experiments. However, measurements using a different instrumented rigid plate apparatus also failed to reveal a concentration of pressure loading at the plate centre [32]. 


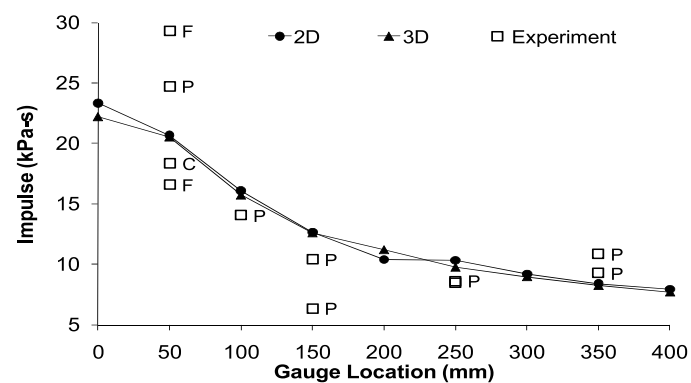

(a)

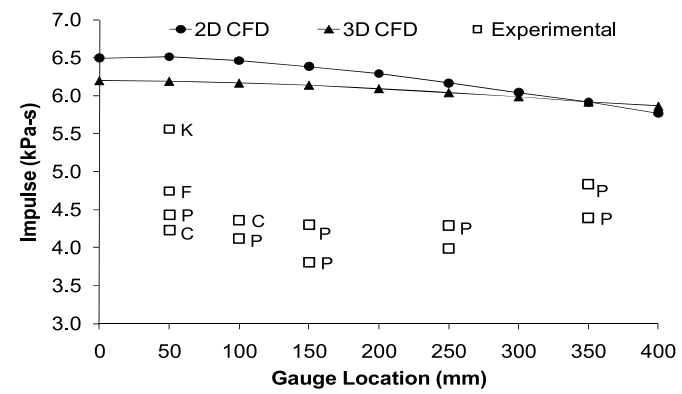

(c)

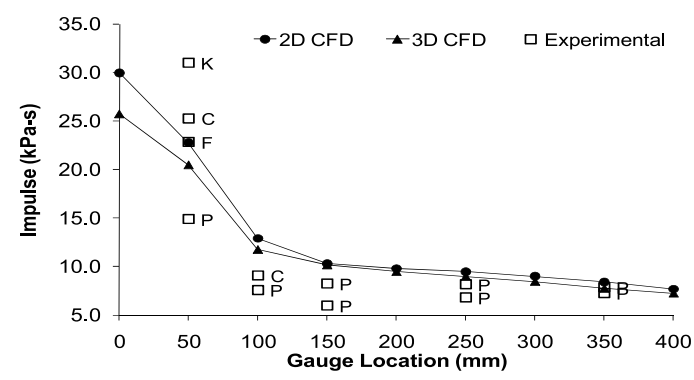

(b)

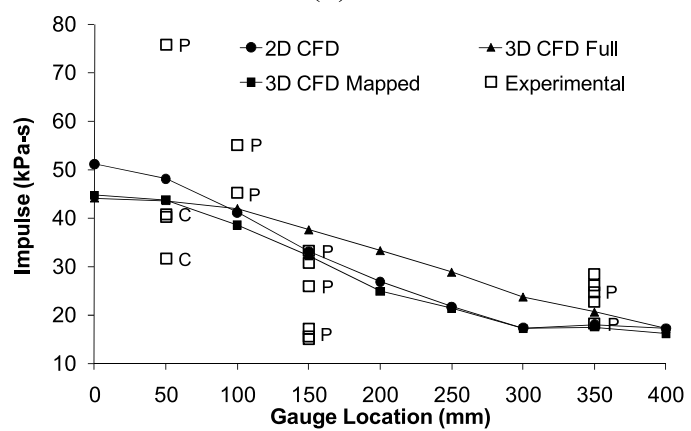

(d)

Fig. 13. Peak impulse associated with the first bubble collapse (a) $40 \mathrm{~g} \mathrm{C} 4$ charge at $0.6 \mathrm{R}$ (b) $40 \mathrm{~g} \mathrm{C} 4$ charge at $1.0 \mathrm{R}$ (c) $40 \mathrm{~g}$ C4 charge at $1.5 \mathrm{R}$ (d) $200 \mathrm{~g} \mathrm{C} 4$ charge at $0.6 \mathrm{R}$.

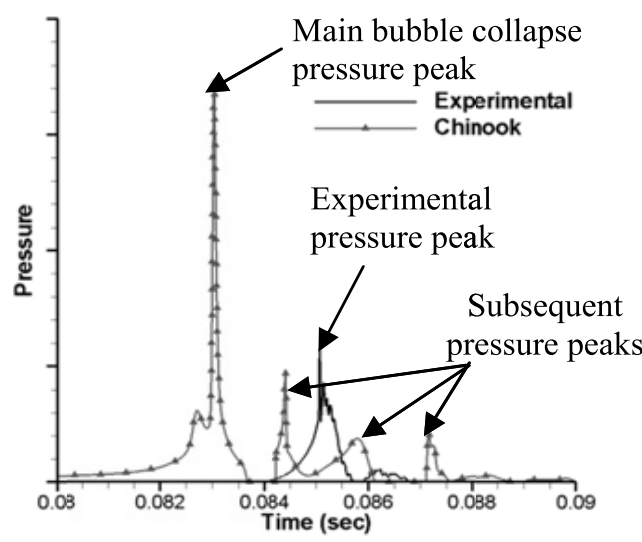

(a)

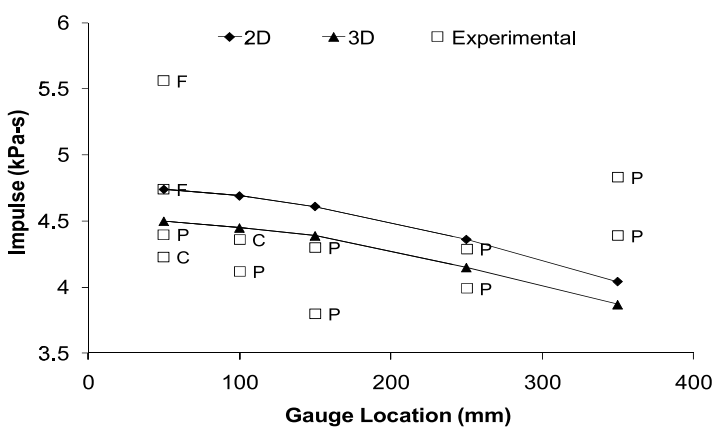

(b)

Fig. 14. (a) Comparison of experimental and Chinook first bubble collapse pressure for the $40 \mathrm{~g}$ C4 charge at $1.5 \mathrm{R}$ (b) Impulse loading comparison with the removal of the subsequent pressure peaks for the first bubble collapse of the $40 \mathrm{~g} \mathrm{C} 4$ charge at a standoff of $1.5 \mathrm{R}(770 \mathrm{~mm})$.

The impulse predictions for the first bubble collapse are generally within $20 \%$ for the piezoelectric gauge results, and often within the experimental range for the piezoelectric measurements. The exception was the $40 \mathrm{~g} C 4 \mathrm{charge}$ at a standoff of $1.5 \mathrm{R}$, which significantly over-predicted the measured impulse loading with differences up to $40 \%$ In this case, pressure peaks subsequent to the main bubble collapse pressure peak were observed in the simulation results that are absent from the measurements, as shown in Fig. 14(a). These additional peaks were found to be related to reflections from the bottom of the basin. By repeating the impulse calculations with only the main pressure peak and ignoring the subsequent peaks, the predicted values were within $13 \%$ of the experimental range, as shown in Fig. 14(b). At this location, the 3D analyses give impulses closer to the measured values. 


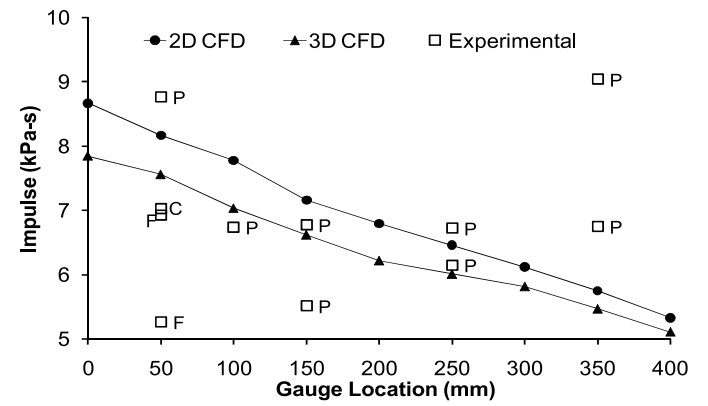

(a)

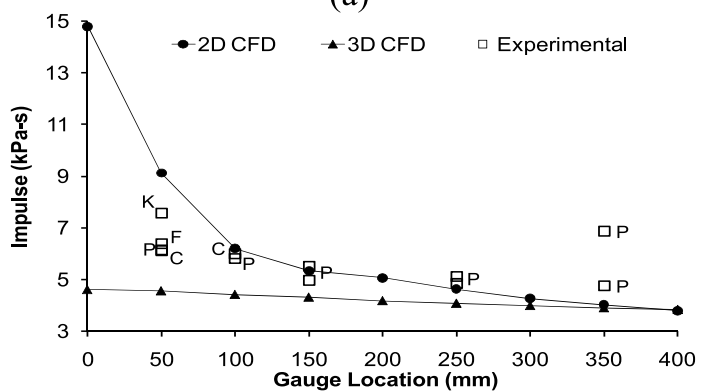

(c)

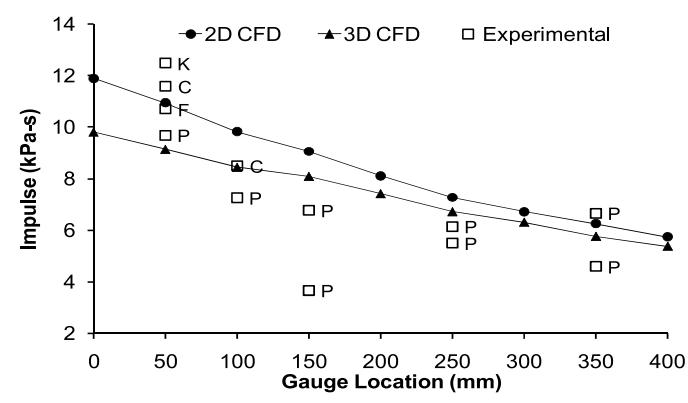

(b)

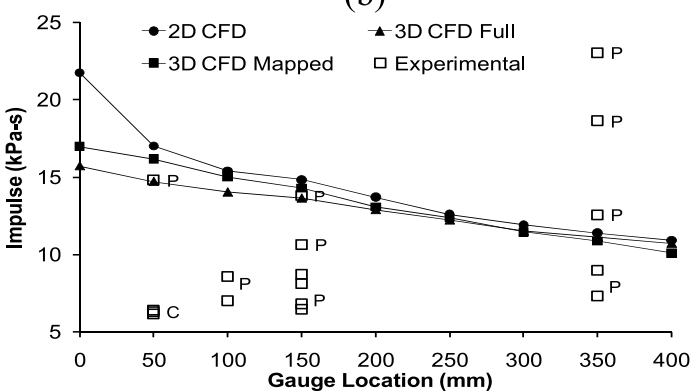

(d)

Fig. 15. Peak impulse comparison for the second bubble collapse (a) $40 \mathrm{~g} \mathrm{C} 4$ charge at $0.6 \mathrm{R}$ (b) $40 \mathrm{~g} \mathrm{C} 4$ charge at $1.0 \mathrm{R}$ (c) $40 \mathrm{~g}$ C4 charge at $1.5 \mathrm{R}$ (d) $200 \mathrm{~g} \mathrm{C} 4$ charge at $0.6 \mathrm{R}$.

Figure 15 compares the experimental and numerical second bubble collapse impulse peaks for the four test cases. The Chinook predictions for the second bubble collapse impulse loading shows similar trends to the first bubble collapse. In general all predictions were within $20 \%$ of the experimental measurements, and were within the variation of the experimental measurements at a significant number of gauge locations. The experimental measurements for the $200 \mathrm{~g}$ charge are relatively low near the center of the plate compared to other locations, which could indicate the onset of gauge failure.

\section{Summary and conclusion}

An extensive numerical modelling study was conducted using the computational fluid dynamics code Chinook to determine its capability to accurately predict the loading on rigid plates subjected to close proximity underwater explosion events. Chinook predictions of the peak pressure, impulse, and time to peak pressure for the shock loading and the first two bubble collapse events were compared to experimental results. The experimental measurements show considerable spatial variability, as well as differences between different gauge types. In all cases it was found that Chinook provides a correct time scale for the bubble collapse events. Qualitatively, Chinook was found to accurately reproduce the general trends in the experimental measurements. Quantitative gaps still remain in the load levels predicted. Overall the three-dimensional simulations provided predictions closer to the experimental measurements than the two-dimensional models.

It was found that the 3D analyses provided better predictions of bubble collapse for the $40 \mathrm{~g}$ charge at standoffs of $0.6 \mathrm{R}$ and $1.0 \mathrm{R}$ and for the $200 \mathrm{~g}$ charge case as compared to the $2 \mathrm{D}$ models. The $3 \mathrm{D}$ analyses run directly from detonation provided slightly better predictions than the mapped approach. The impulse predictions for all of the models were within $15 \%$ for the full three-dimensional models, $20 \%$ for the mapped three-dimensional models, and $30 \%$ for the two-dimensional domain models. The full three-dimensional analysis significantly under-predicted the shock pressure compared to the two-dimensional shock propagation models. Chinook impulse predictions were closer to the experimental results for the shock loading than the bubble collapses. Charge size seems to have little effect on the agreement with experiments. The initial standoff has a small effect on the bubble collapse load 
predictions, but the shock pressures did deviate further from the experimental measurements as the initial standoff increased. For the 2D analyses, the mesh refinement does not produce a clear trend on the bubble collapse peak pressure predictions, as they fluctuate both up and down as the mesh is further refined. For overall load predictions the three-dimensional mapping approach seems to be the best approach. Reasons include the reduced computational time and the better shock loading predictions derived from using a refined two-dimensional model for the initial shock phase.

A material interface tracker is being implemented in Chinook at the time of writing. This would allow for the boundary between the gas bubble and the surrounding water to be better defined and the plate displacement to be accurately represented in the loading calculations of flexible targets. In this study it was shown that the pressure loading is over-predicted by Chinook compared to experiments. Maintaining the correct bubble density should reduce the pressure loading upon collapse, and thus result in better overall agreement with experiments and better convergence of the two-dimensional models to the experimental results. Experience with other hydrocodes suggests that the cut-off pressure used for cavitation initiation significantly influences the loading results for two-dimensional axisymmetric simulations [3]. Currently the cavitation cut-off value in Chinook is not adjustable, but this will be addressed in future developments.

In this study, the experimental results and Chinook predictions were compared with analytical and similitude-based models of bubble growth. Chinook predicted the gas bubble period better than any of these approaches. It was also shown that a hemispherical close-proximity analytical model was found to predict the first bubble period for initial standoffs within one bubble radius somewhat better than the free field models. Further development of the close-proximity analytical model is planned, including prediction of loading effects.

\section{References}

[1] J.E. van Aanhold and T.N. Bosman, Nearby UNDEX Tests on a Thick Plate, 76th Shock and Vibration Symposium, Destin, FL, 2005.

[2] J.M. Brett and G. Yiannakopolous, A study of explosive effects in close proximity to a submerged cylinder, International Journal of Impact Engineering 35 (2007), 206-225.

[3] G. Harris Private Communication, 2010.

[4] T.E. Dunbar, Modelling of Close-Proximity Underwater Explosion Loads and Structural Response - Phase 1, DRDC Atlantic Contractor Report CR 2008-272.

[5] T.E. Dunbar, Modelling of Close-Proximity Underwater Explosion Loads and Structural Response - Phase 2, DRDC Atlantic Contractor Report CR, 2009-180, 2009.

[6] L. Fried, W. Howard, P. Souers and P. Vitello, Cheetah 3.0 User's Manual, Energetic Materials Center, Lawrence Livermore National Laboratory, 2001.

[7] T.L. Geers and K.S. Hunter, Dilatation dynamics of an underwater explosion bubble, Proceedings of the 67th Shock and Vibration Symposium, Monterey, CA, USA, 1996.

[8] D.C. Gibson and J.R. Blake, The growth and collapse of bubbles near deformable structures, Journal of Applied Science Research 38 (1982), 215-224.

[9] J. Gregson, T. Dunbar and J Lee, Simulation of Structural Failure from Contact Underwater Explosions, 78th Shock and Vibration Symposium, 2007.

[10] C. Herring, 1941, Theory of the pulsation of the gas bubble produced by an underwater explosion, in Underwater Explosion Research Volume II, Office of Naval Research, Washington, D.C., 1950, pp. 35-131.

[11] K.S. Hunter, Underwater Explosion Bubble Dynamics, MSc Dissertation, University of Colorado, 1996.

[12] S. Iakovlev, Submerged fluid-filled cylindrical shell subjected to a shock wave: fluid-structure interaction effects, Journal of Fluids and Structures 23 (2007), 117-142.

[13] K.M. Kalumuck, G.L. Chahine and R. Duraiswami, Analysis of the response of a deformable structure to underwater explosion bubble loading using a fully coupled fluid-structure interaction procedure, Proceedings of the 66th SAVIAC Shock and Vibration Symposium, Biloxi, MS, 1995.

[14] K.K. Kan, J.H. Stuhmiller and P.C. Chan, Simulation of the collapse of an underwater explosion bubble under a circular plate, Journal of Shock and Vibration 12 (2005), 217-225.

[15] J.B., Keller and I.I., Kolodner, Damping of underwater explosion bubble oscillations, J Applied Phys 27 (1956), $1152-1161$.

[16] J.G. Kirkwood and H. Bethe, The pressure wave produced by an underwater explosion I. (OSRD no. 588), in: Shock and Detonation Waves, W.W. Wood, ed., Gordon and Breach, New York, 1967, pp. 1-34.

[17] E. Klaseboer, K.C. Hung, C. Wang, C.W. Wang, B.C. Khoo, P. Boyce, S. Debono and H. Charlier, Experimental and Numerical investigation of rthe dynamics of an underwater explosion bubble near a resilient/rigid structure, Journal of Fluid Mechanics 537 (2005), 387-413.

[18] H. Jones and A.R. Miller, The detonation of solid explosives, Proc R Soc London Ser. A 194A (1948), $480-507$.

[19] H. Lamb, The early stages of a submarine explosion, Philos Mag 45(Ser 6) (1923), 257-265.

[20] B. Legrand, N. Leconte, A. Menegazzi and T. Millot, Submarine hull integrity under blast loading, International Journal of Impact Engineering 36 (2009), 1070-1078. 
[21] E.L. Lee, H.C. Hornig and J.W. Kury, Adiabatic expansion of high explosive detonation products, Lawrence Livermore National Laboratory Technical Report UCRL-50422, 1968.

[22] J.J. Lee, J. Gregson, G. Rude and G.T. Paulgaard, Underwater shock and bubble interactions from twin explosive charges, Presented at the 26th International Symposium on Shock Waves, Göttingen, Germany, 15-20 July 2007.

[23] J.J. Lee, M.J. Smith, J. Huang and G.T. Paulgaard, Deformation and rupture of thin steel plates due to cumulative loading from underwater shock and bubble collapse, Proceedings of the 79th SAVIAC Shock and Vibration Symposium, Orlando, FL, 2008.

[24] J.J. Lee. Private communication, 2011.

[25] Z. Liu, W. Xie and Y. L. Young, Numerical modeling of complex interactions between underwater shocks and composite structures, Computational Mechanics 43 (2009), 239-251.

[26] Martec Ltd., Chinook Manual SM-01-01 Rev 4, Halifax, N.S., Canada, 2008.

[27] S. Menon, Experimental and Numerical Studies of Underwater Explosions, Annual report for Grant No. N00014-91-J-1993, Office of Naval Research, 1996.

[28] R. Rajendran and K Narasimhan, Underwater shock response of circular HSLA steel plates, Shock and Vibration 7 (2000), $251-262$.

[29] R. Rajendran and K. Narasimhan, Deformation and fracture behaviour of plate specimens subjected to underwater explosion - a review, International Journal of Impact Engineering 32 (2006), 1945-1963.

[30] K. Ramajeyanthilagam, C.P. Vendhan and V. Bhujanga Rao, Experimental and numerical investigations on deformation of cylindrical shell panels to underwater explosion, Shock and Vibration 8 (2001), 253-270.

[31] K. Ramajeyanthilagam and C.P. Vendhan, Deformation and rupture of thin rectangular plates subjected to underwater shock, International Journal of Impact Engineering 30 (2004), 699-719.

[32] M.J. Riley, Modelling of Gas Bubble Behaviour and Loading on a Rigid Target due to Close-Proximity Underwater Explosions: Comparison to Tests Conducted at DRDC Suffield, DRDC Atlantic TM 2010-238, Defence R\&D Canada - Atlantic, Nov 2010.

[33] M. Shiffman and B. Friedman, 1943, Studies on the gas bubble resulting from underwater explosions: On the best location of a mine near the sea bed, in Underwater Explosion Research Volume II, Office of Naval Research, Washington, D.C., 1950, $247-320$.

[34] J.-F. Sigrist and C. Leblond, Une méthode semi-analytique pour l'analyse de l'interaction entre une onde de choc et une coque élastique immergée. Application au pré-dimensionnement de coques de sous-marins, Mecanique \& Industries 9 (2008), 543-550. In French.

[35] J. Slater and G. Rude, Loading and response of flat plate targets from close-proximity underwater explosions, Proceedings of the 71st SAVIAC Shock and Vibration Symposium, Arlington, Va., 2000.

[36] J. Slater and G. Rude, Loading and Damage to Small-Scale Cylinder Targets from Close-Proximity Underwater Explosions, DRDC Suffield Technical Report TR 2004-053.

[37] J. Slater, G. Rude and G. Paulgaard, Experimental study of air-backed and water-backed targets during near-contact explosions, DRDC Suffield Technical Report \# TR 2005-152, 2005.

[38] G.I. Taylor, 1942, Vertical Motion of a spherical bubble and the pressure surrounding it, in Underwater Explosion Research Volume II, Office of Naval Research, Washington, D.C., 1950, 131-144.

[39] A. Wardlaw and J.A. Luton, Fluid structure interaction mechanisms for close-in explosions, Journal of Shock and Vibration, 7(5) (2000), $265-275$.

[40] K.G. Webster, Investigation of Close Proximity Underwater Explosion Effects on a Ship-Like Structure Using the Multi-Material Arbitrary Lagrangian Eulerian Finite Element Method, MSc Thesis, Dept of Ocean Engineering, Virginia Polytechnic Institute and State University, 2007. 

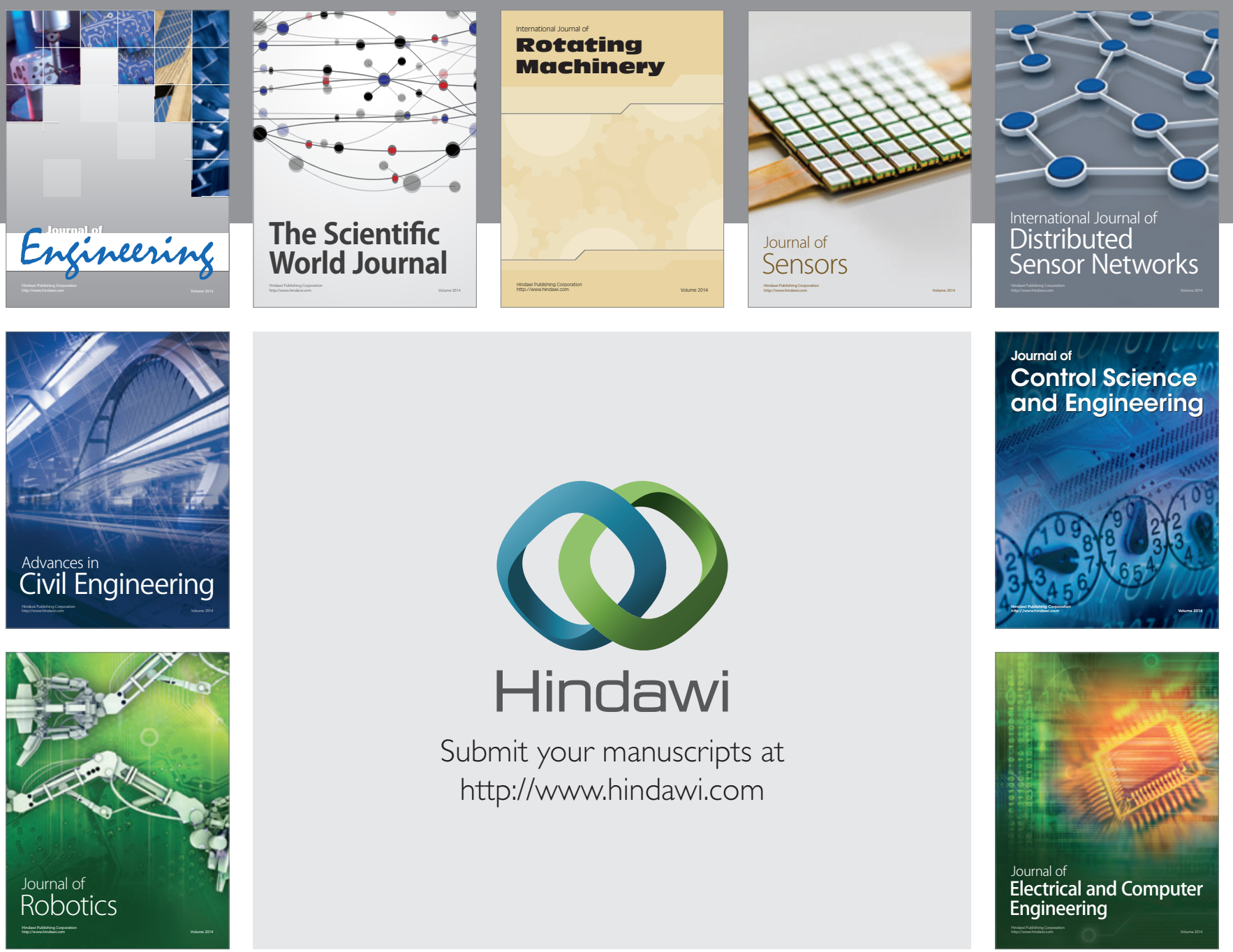

Submit your manuscripts at

http://www.hindawi.com
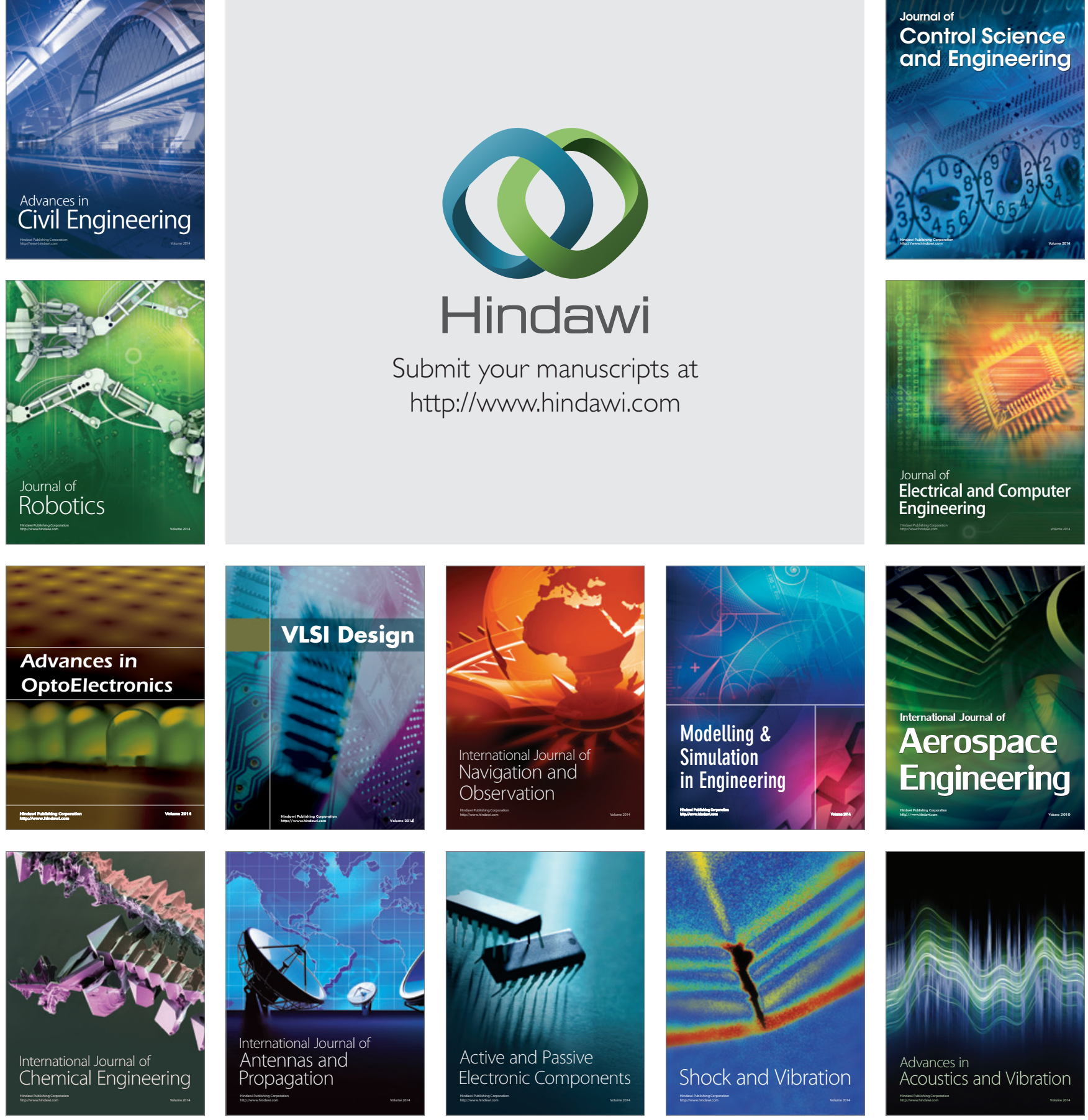